\title{
Electronic support tools for identification and management of rice weeds in Africa for better-informed agricultural change agents
} \author{
and Pascal Marnotte ${ }^{2}$

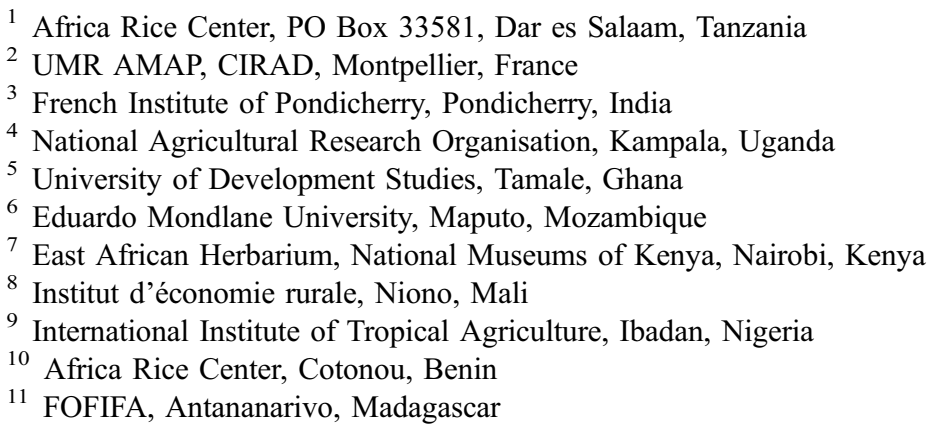

Jonne Rodenburg ${ }^{1, *}$, Thomas Le Bourgeois ${ }^{2}$, Pierre Grard ${ }^{2,3}$, Alain Carara ${ }^{2}$, Runyambo Irakiza ${ }^{1}$, Derek Wambulwa Makokha ${ }^{1}$, Ruth Kabanyoro ${ }^{4}$, Israel Dzomeku ${ }^{5}$, Tomas Chiconela ${ }^{6}$, Itambo Malombe ${ }^{7}$, Soungalo Sarra ${ }^{8}$, Friday Ekeleme ${ }^{9}$, Mariame Mariko ${ }^{10}$, Alain Paul Andrianaivo ${ }^{11}$

\begin{abstract}
We developed an interactive electronic weed identification tool, AFROweeds, and an online network, Weedsbook, for agricultural change agents to aid communication and offer assistance to rice farmers with specific weed problems. We collected quantitative and qualitative data to assess effectiveness and usefulness of these products with potential users. With the online version of AFROweeds, used on an electronic tablet, average weed identification time in the field was 7 min $6 \mathrm{~s}$ with $44 \%$ successful identifications. Poor mobile network coverage and slow internet were the main reasons for the relative long identification time and low success rate. A second trial was done with the offline version, preinstalled on a tablet. The average identification time was $6 \min 34 \mathrm{~s}$, with a success rate of $75 \%$. The online network Weedsbook, established alongside AFROweeds, was assessed by the test users as a useful additional aid, enabling agricultural change agents and agronomists to exchange information or request assistance on all aspects of weeds and weed management. The potential improvements of both products are discussed.
\end{abstract}

Keywords: rice / extension / lowland / sub-Saharan Africa / ICT / network

Résumé - Des outils électroniques d'aide à l'identification et à la gestion des adventices du riz en Afrique pour des agents de vulgarisation agricole mieux informés. Afin que les agents de vulgarisation agricole puissent aider rapidement et efficacement les riziculteurs à améliorer leurs pratiques de désherbage, nous avons développé un outil électronique d'identification des adventices du riz, AFROweeds, et un espace collaboratif en ligne, Weedsbook. Nous avons collecté des donnéees qualitatives et quantitatives pour évaluer l'efficacité et l'utilité de ces produits avec des utilisateurs potentiels. Le premier test d'AFROweeds a été mis en œuvre avec la version en ligne (par 3G), à partir d'une tablette électronique. Le temps d'identification moyen d'une espèce a été de $7 \min 6 \mathrm{~s}$ avec un taux de réussite de $44 \%$. Une faible couverture du réseau mobile et la lenteur du réseau internet ont été les principales raisons de la longue durée d'identification et du faible taux de réussite. Le deuxième essai, hors-ligne, a été réalisé avec la version encapsulée, installée sur une tablette. Le temps d'identification moyen a été de $6 \mathrm{~min} 34 \mathrm{~s}$, avec un taux de réussite de $75 \%$. Le réseau Weedsbook, établi en plus d'AFROweeds, a été évalué par des utilisateurs

*Corresponding author: j.rodenburg@cgiar.org 
potentiels comme une aide additionelle utile qui permet aux agents de vulgarisation agricole d'échanger des informations ou de demander de l'aide sur les mauvaises herbes et leur gestion. Les potentiels d'améliorations de ces outils sont discutés.

Mots clés : riz / conseil agricole / adventice / bas-fond / Afrique sub-saharienne / TIC / réseau

Rice (Oryza sativa L. and O. glaberrima Steud.) is an important staple food in sub-Saharan Africa (SSA), and is grown locally by millions of small-scale farmers. Productivity of these smallholder rice production systems is generally poor (Seck et al., 2013). Rice that is cultivated in lowlands have a higher yield potential than rice grown in uplands, mainly because of the higher availability of water (Camara et al., 2008). But even in lowland rice growing environments, yields derived by smallholders is suboptimal, with an average estimated productivity for SSA of $1.9 \mathrm{tha}^{-1}$ in rainfed and $2.2 \mathrm{tha}^{-1}$ in irrigated or permanently inundated lowlands (Diagne et al., 2013). Competition from weeds is one of the commonest and most important yield-reducing factors in lowland rice production systems in SSA (Nhamo et al., 2014; Seck et al., 2012).

While African rice farmers often know the weed species they commonly encounter in their fields, at least by their vernacular names, they predominantly lack the necessary knowledge and means for effective weed management (Rodenburg and Johnson, 2009). Agricultural researchers, extension agents, crop protection and farmer advisory services, hereafter referred to as agricultural changes agents, on the other hand, are often not equipped enough to provide effective and locally adapted weed management advices to farmers (Schut et al., 2015a) and this is mainly caused by insufficient attention devoted to this type of production constraints at agricultural colleges and universities in this region (Schut et al., 2015b) and insufficient availability of published knowledge in this domain. To assist current and future agricultural change agents in communicating and helping rice farmers with specific weed problems in their fields, we initiated the development of electronic means of support.

Weed identification is considered a critical first step for targeted weed management (Zimdahl, 2007), but accurate and timely identification requires specialized knowledge and skills rarely available among agricultural change agents working in the field. For that reason, a user-friendly support tool for the identification of rice weeds was one of our primary development aims. We coupled this identification tool, called AFROweeds, to a database with information on local names, biology, ecology and management and an online collaborative network, called Weedsbook, enabling users to find more information on aspects like weed ecology and management and to exchange with experts.

While electronic aids for weed species identification have been released before (e.g. Grard et al., 2006, 2010; Le Bourgeois et al., 2008), an identification tool for weeds of lowland rice in Africa, containing information on vernacular names and management recommendations for local species, and adapted for assistance to African rice farmers, has not been previously developed. Until recently, agricultural change agents and students working on rice in Africa had to rely on - relatively outdated - field guides and textbooks for the identification of weeds, such as the bilingual (English/French) work by Johnson (1997) for rice weeds in West Africa, or the
English-language guides by Akobundu and Agyakwa (1987) for general weeds in West Africa. Others include Ivens (1989) for general weeds in East Africa and the French-language guide for general weeds in Central Africa by Le Bourgeois and Merlier (1995). The AFROweeds tool focuses on weeds in rice and covers all relevant African regions. The tool is available in two languages (English and French) and provides a userfriendly identification aid, leading to factsheets containing additional information on local names, ecology, biology, local uses, and control rather than just the usual photos, drawings, and taxonomic descriptions in the aforementioned books. Inclusion of local names in the database will enhance the communication between agricultural change agents and farmers. The network Weedsbook was set up to enable those users to exchange with peers and experts to get guidelines and answers to additional queries or to exchange experiences and observations.

The products generated by this initiative, i.e. the identification tool, database and network, may not necessarily be accessible and useful by small-scale farmers in SSA, as their use requires a certain level of education and access to smartphones and internet. The intended users are rather the current and future actors that work in farmer support systems. This actor group primarily includes staff of the national agricultural research and extension systems (NARES), like extension services, public crop protection agents and field technicians and researchers of national research organizations and universities. Lecturers and researchers can use these tools to train students at agricultural colleges and universities.

The objective of this study was to evaluate the performance and usefulness of the tool, database, and network, and to assess whether and how these products should be improved. To this end we put them to test among a group of potential users.

\section{Materials and methods}

\subsection{Partnership}

The team behind the development of these products consisted of weed scientists and botanists from the Centre de coopération internationale en recherche agronomique pour le développement (Cirad) and Africa Rice Center (AfricaRice), and staff of the NARES from 14 African countries (Kenya, Madagascar, Mozambique, Rwanda, Tanzania and Uganda in East and Southern Africa, and Benin, Burkina Faso, Chad, Côte d'Ivoire, Ghana, Mali, Nigeria, and Senegal in West and Central Africa). The most important collaborating institutes were: National Agricultural Research Organisation (NARO) in Uganda, University for Development Studies (UDS) in Ghana, Eduardo Mondlane University (EMU) in Mozambique, East African Herbarium (EAH) in Kenya, Institut d'économie rurale (IER) in Mali, Michael Okpara University of Agriculture (MOUA) in Nigeria and Centre national malgache de recherche appliquée au développement rural (FOFIFA) in Madagascar. 


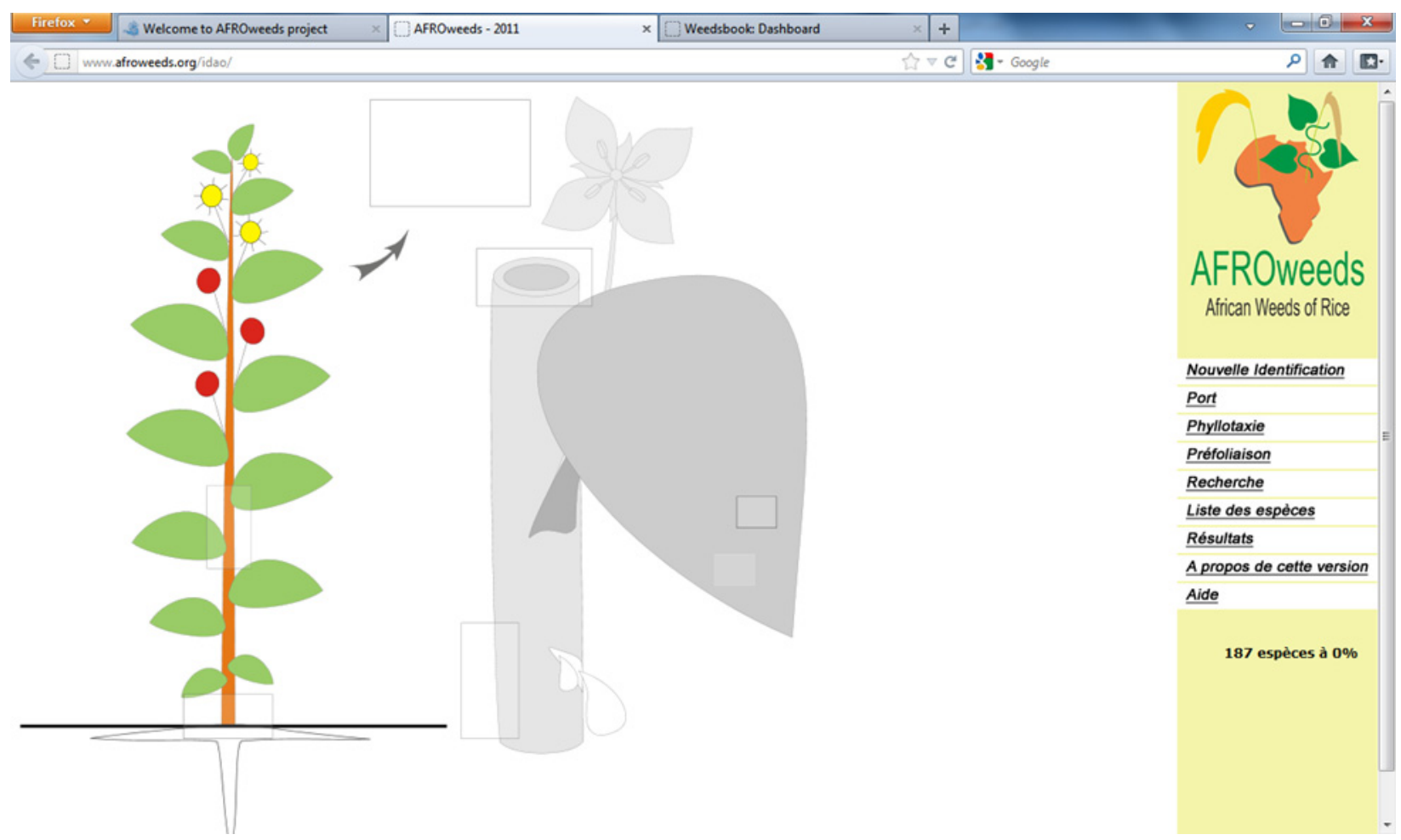

Fig. 1. Interface of the IDAO weed identification tool AFROweeds.

Fig. 1. Interface de l'outil d'identification des mauvaises herbes IDAO AFROweeds.

\subsection{AFROweeds, an electronic identification tool and database on rice weeds}

We developed an interactive electronic tool and database for computers, electronic tablets, and smartphones called AFROweeds. The idea of electronic tools for identification of pests or diseases in crops is not new. Pertot et al. (2012), for instance, developed a tool to identify plant diseases, while several previous tools have been developed for weed identification. Examples of such tools are Adventrop, for general weeds in the Sudano-sahelian zone of Africa (Grard et al., 2010); AdventOI, for weeds in Indian Ocean islands (Le Bourgeois et al., 2008); and OSWALD, for major weeds in rice paddies of Cambodia and Lao People's Democratic Republic (Grard et al., 2006). Like Adventrop, AdventOI, and OSWALD, the $A F R O$ weeds identification tool is a computer program (also called identikit), based on IDAO, an open-source plant identification software with an interactive graphical interface and supported by a database. AFROweeds is available online (www.weedsbook.org/idao), as a CD-ROM (Grard et al., 2012) for use offline as a program on a desktop or laptop, or as an application on smartphones or electronic tablets (currently available in the App store, Apple Inc.). All formats, whether online, CD-ROM, or App, have a similar interface (Fig. 1). The identikit enables the user to select common and important morphological character states (such as flower color, leaf shape, stem shape or form) of the plant under consideration and to indicate in the pictorial multiple-choice menu what the character looks like (Fig. 2A-F). The identikit calculates the probability of the species' identity corresponding to the combination of choices. The user can view a list of species with percentages of fit with the selected character shapes, forms, or colors, and check the most likely species (e.g., those with $100 \%$ fit) with the actual plant to be identified (Fig. 2G). Clicking on the species names in the list provides access to species' pages from the database with information on botanical descriptions, ecology, biology, management, and local uses (Fig. 2H). Users can also compare the plant being examined with field and herbarium photos or illustrations. The AFROweeds identikit currently (Sept. 2015) contains close to 200 species encountered in Africa, primarily for lowland rice. The database can also be consulted directly, hence without any identification, by clicking on 'Results' which opens the list of species alphabetically sorted.

\subsection{Weedsbook, the online exchange platform on weeds}

Apart from the tool, the team established a bilingual (English/French) online exchange platform called Weedsbook - the African Weed Science Network (www.weedsbook.org). Weedsbook is an open-access network that enables agricultural change agents to exchange information or request assistance on all aspects of weeds and weed management. Weedsbook contains discussion groups on different aspects, such as weed identification, weed management, parasitic weeds, and relevant conferences and publications. It also hosts resources like relevant scientific publications, guides to weed identification, management recommendations for groups of species 

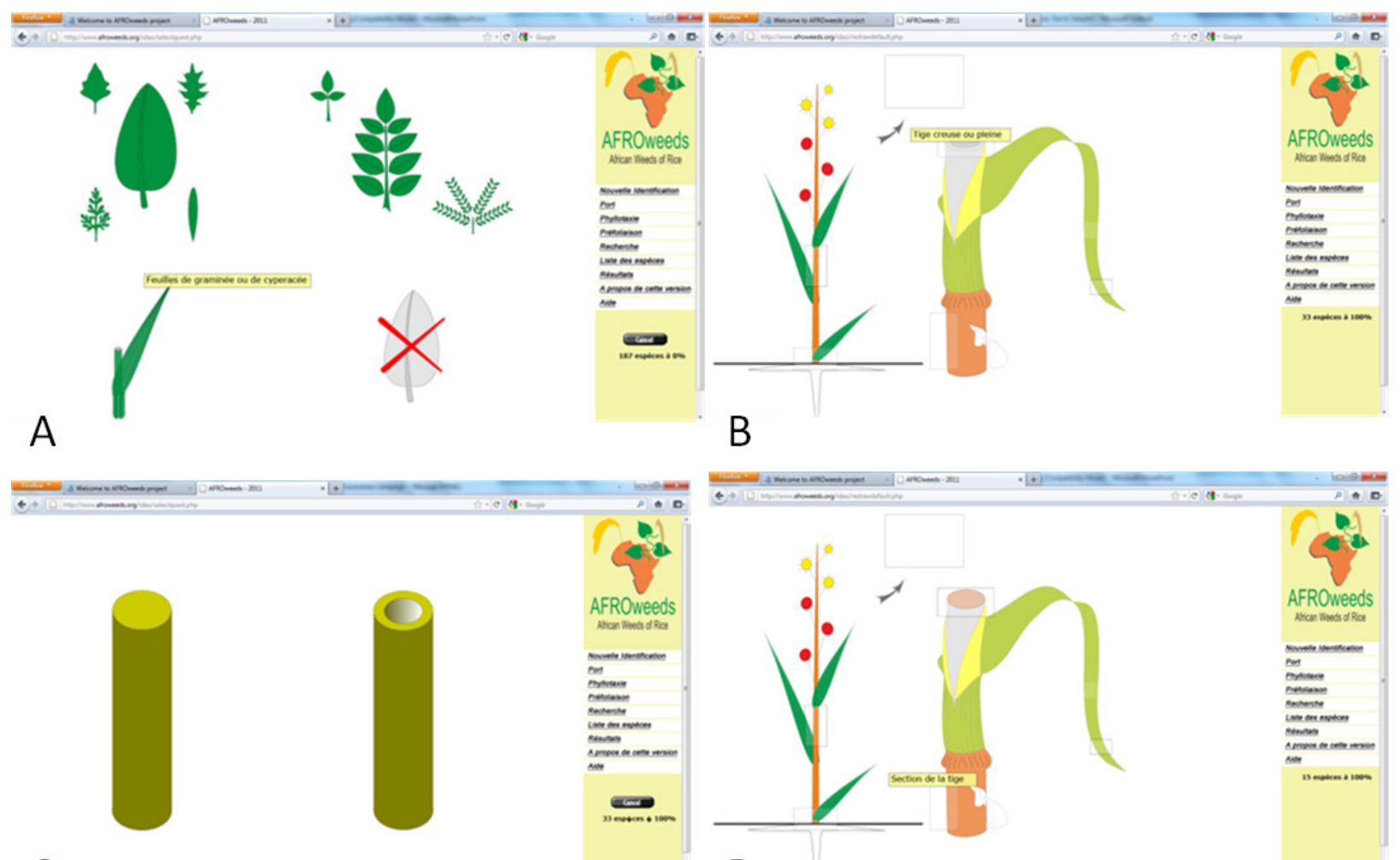

C
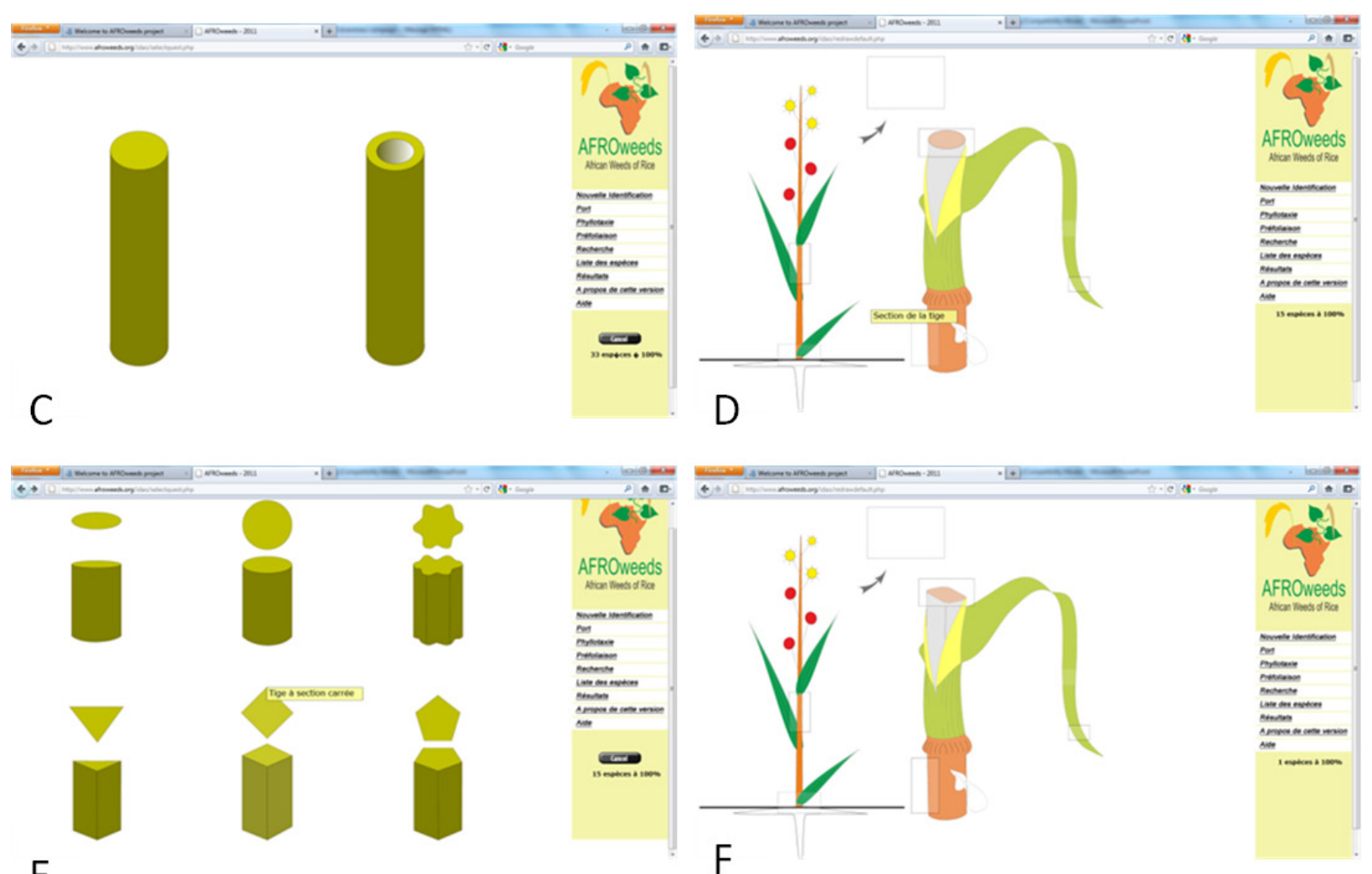

E

F

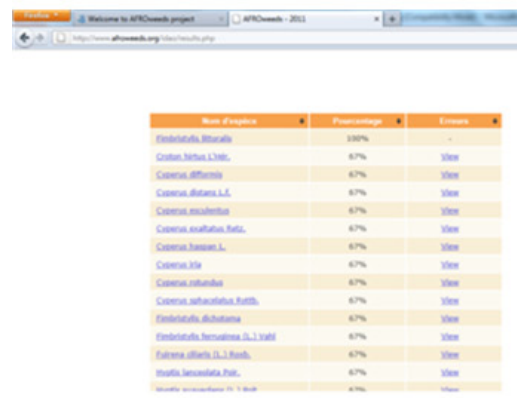

G
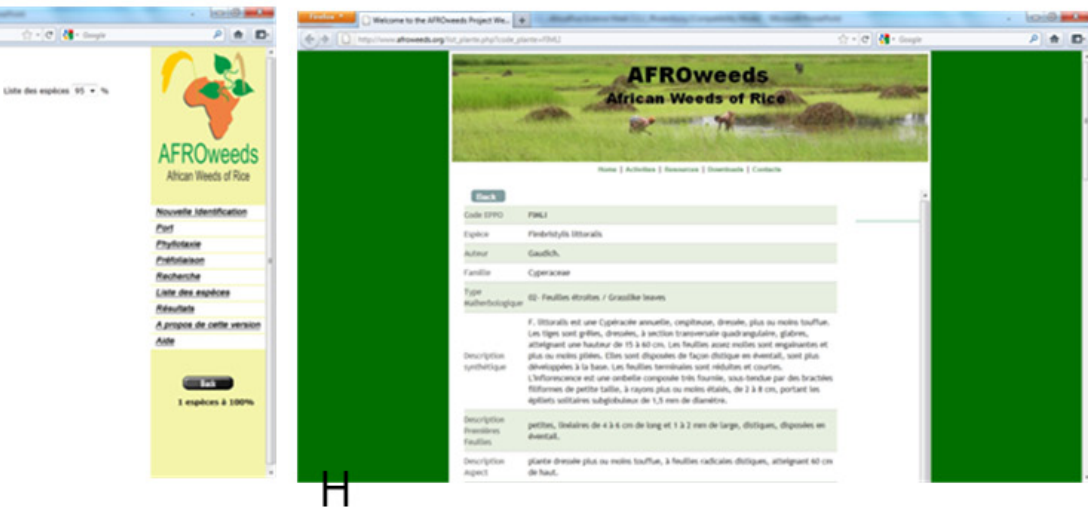

Fig. 2. Example of a stepwise identification of a weed species using the multiple-choice menu of AFROweeds. A: selecting the leaf shape; B, C: selecting the stem filling; D, E: selecting the stem section shape; F, G: the result; H: the species datasheet.

Fig. 2. Exemple d'une identification par étapes d'une espèce de mauvaise herbe en utilisant le menu à choix multiples d'AFROweeds. A : la sélection de la forme de la feuille; $B, C$ : la sélection de la vacuité de la tige ; $D, E$ : la sélection de la forme de la section de la tige ; F, $G$ : le résultat ; $H$ : la fiche espèce. 
(annual/perennial grasses, annual/perennial sedges, annual/ perennial broad-leaved weeds, aquatic weeds, and parasitic weeds), and information on research grants and scholarships. Moreover, members can exchange through discussion forums, ask questions or request assistance - concerning, for example the identification of weed species encountered. It enables members to share relevant news such as outcomes from their work. As of September 2015, it had 336 individual members. The network is composed of staff of university and research \& training organizations (63\%), students $(26 \%)$, extension agents and crop protection service providers $(10 \%)$ and staff of NGO's $(1 \%)$. They are mainly based in Africa $(91 \%)$ and Europe $(9 \%)$ and predominantly male $(76 \%)$. Each member can compose a profile with personal and professional information, contact details, and relevant internet links.

\subsection{Testing the tool, database and network by potential users}

We organized a workshop in Cotonou, Benin, from 24 to 26 September 2012, with 13 potential users of the tool, database and network. This test group consisted of research, development and extension staff of African NARES from 11 different countries (Benin, Burkina Faso, Côte d'Ivoire, Ghana, Kenya, Madagascar, Mali, Mozambique, Nigeria, Senegal, and Uganda). The workshop was facilitated by 8 staff members of Cirad and AfricaRice. During the workshop, we enabled the participants to work with the three products - the identification tool, the species database, and the online network - and we facilitated discussion among them. Discussion points were whether or not the products are generally useful and desired, whether they are easy to use, and whether they generate effective and useful results. Opinions and discussions were noted. We also started an online (bilingual) discussion on Weedsbook itself. Comments by members in general, and workshop participants in particular, were gathered (see, e.g., Fig. 3).

The AFROweeds identification tool was also put to test in farmer-owned rice fields. A first trial was carried out on 20 June 2012 in Ruvu, Tanzania $\left(6^{\circ} 43 / 45 / / \mathrm{S} \mathrm{38} 40 / 54 / / \mathrm{E}\right)$ with a group of 7 potential users, derived from NARES of Kenya, Mozambique, Rwanda, Tanzania and Uganda. In this test, the online version of the tool was used, on an electronic tablet (iPad 3, 32 GB, Apple Macintosh) with 3G data SIM card. The tool was tested by 1-2 persons for each identification attempt and a total of 9 attempts were made, covering 8 species. For the second trial, on 25 September 2012, an encapsulated offline version of $A F R O$ weeds was installed on three electronic tablets (iPad 3, $32 \mathrm{~GB}$, Apple Macintosh). This trial was conducted in Zoungo, Ouémé valley, Benin $\left(7^{\circ} 06 / 46 / / \mathrm{N}\right.$ $2^{\circ} 30 / 58 / /$ E) with the previously mentioned workshop delegates from NARES of 11 different African countries. Teams of 2-3 persons were composed in the field to practice and test the system. This test comprised 16 identification attempts, covering 12 species. In both user tests, the users randomly selected the specimen of weeds from the weed flora encountered in the farmer's rice fields. For each attempt we noted the species name, irrespective of the success of identification, the time required for each attempt (measured with stopwatches), and whether or not the identification was successful.

Qualitative data derived from group discussions were ordered manually for analyses and interpretation. On quantitative data, derived from field tests, descriptive statistics were computed using MS Excel (2007).

\section{Results and discussion}

\subsection{Testing and discussing the AFROweeds identification tool}

The first test in Ruvu, Tanzania, with the online version of the tool resulted in an average identification time of $7 \min 6 \mathrm{~s}$, ranging from $1 \mathrm{~min} 42 \mathrm{~s}$ to $11 \mathrm{~min} 50 \mathrm{~s}$, with 4 successful identifications out of 9 , hence $44 \%$ (Tab. 1). Suboptimal $3 \mathrm{G}$ network coverage in the field, causing slow and intermittent internet, led to long identification times and even some complete failures. In one case (Melochia corchorifolia L.), identification failed due to a lack of options to characterize the leaf morphology to sufficient detail.

The second trial was done using the offline version (a tablet application). The offline version does not depend on network availability. Calculated over 16 identification attempts, the average identification time was 6 min $34 \mathrm{~s}$, ranging from $1 \mathrm{~min} 14 \mathrm{~s}$ to $10 \mathrm{~min} 16 \mathrm{~s}$, with 12 successful identifications - a success rate of $75 \%$ (Tab. 1). Identifications were unsuccessful when the species was not yet included in the database, or when the user made an early mistake in the selection procedure. As none of the evaluators had previous experience with the tool, it is likely that with more practice the success rate would increase and the time to identification decrease.

The various comments from the test users indicated that the identification tool worked well and made it easy to identify the species, especially of broad-leaved weeds which usually have more distinct and eye-catching characteristics (e.g. flower colors, leave shapes, plant morphology and habits) compared to grasses and sedges. Variations in flower color within species, however, need to be included in the tool. The identification of sedges was more difficult because there were not (yet) enough distinctive characters included in the tool. For example, the bract length and the characteristics of the bulbs of the sedges needed to be more specific. However, as test users noted, even if the identification of a species does not result in a single outcome, as a result of the above-mentioned or any other constraint, the tool will still be useful in narrowing down the options and from there the user can conclude the identification by using the descriptions or photos in the database or by using field guides.

There was broad consensus among participants that the tool and database should be enhanced by including (1) more species, (2) more local names of species and (3) more information on local uses (e.g., food, fodder, medicinal, or agricultural uses) of species. Adding local names of species would facilitate discussions with farmers who know the species only by their vernacular names. The suggestion to enhance the AFROweeds tool and database with species already covered by other tools such as Adventrop was also broadly supported by participants. During the workshop, it was also mentioned that the translation of the database into other languages such as 


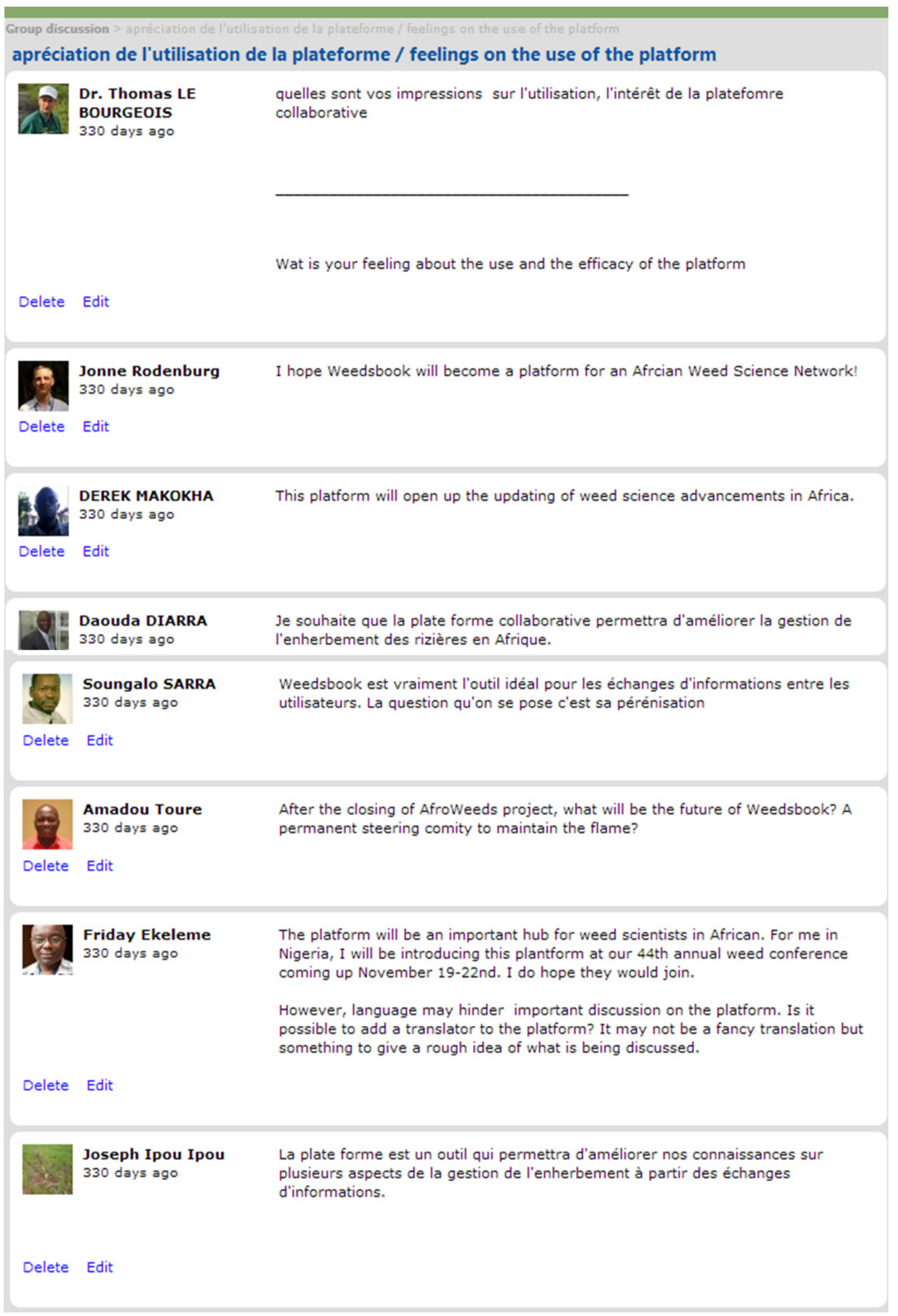

Fig. 3. Excerpt of the online discussion on the collaborative platform Weedsbook, on the subject 'feelings on the use of the platform'.

Fig. 3. Extrait de la discussion en ligne sur la plate-forme collaborative Weedsbook, sur le thème " appréciation d'utilisation de la plate-forme ». 
Table 1. Results of the field test of the iPad-supported version of the AFROweeds weed identification tool for lowland rice in Africa. Table 1. Résultats de l'essai au champ d'AFROweeds : identification des mauvaises herbes du riz de bas-fond en Afrique - version IOS pour iPad.

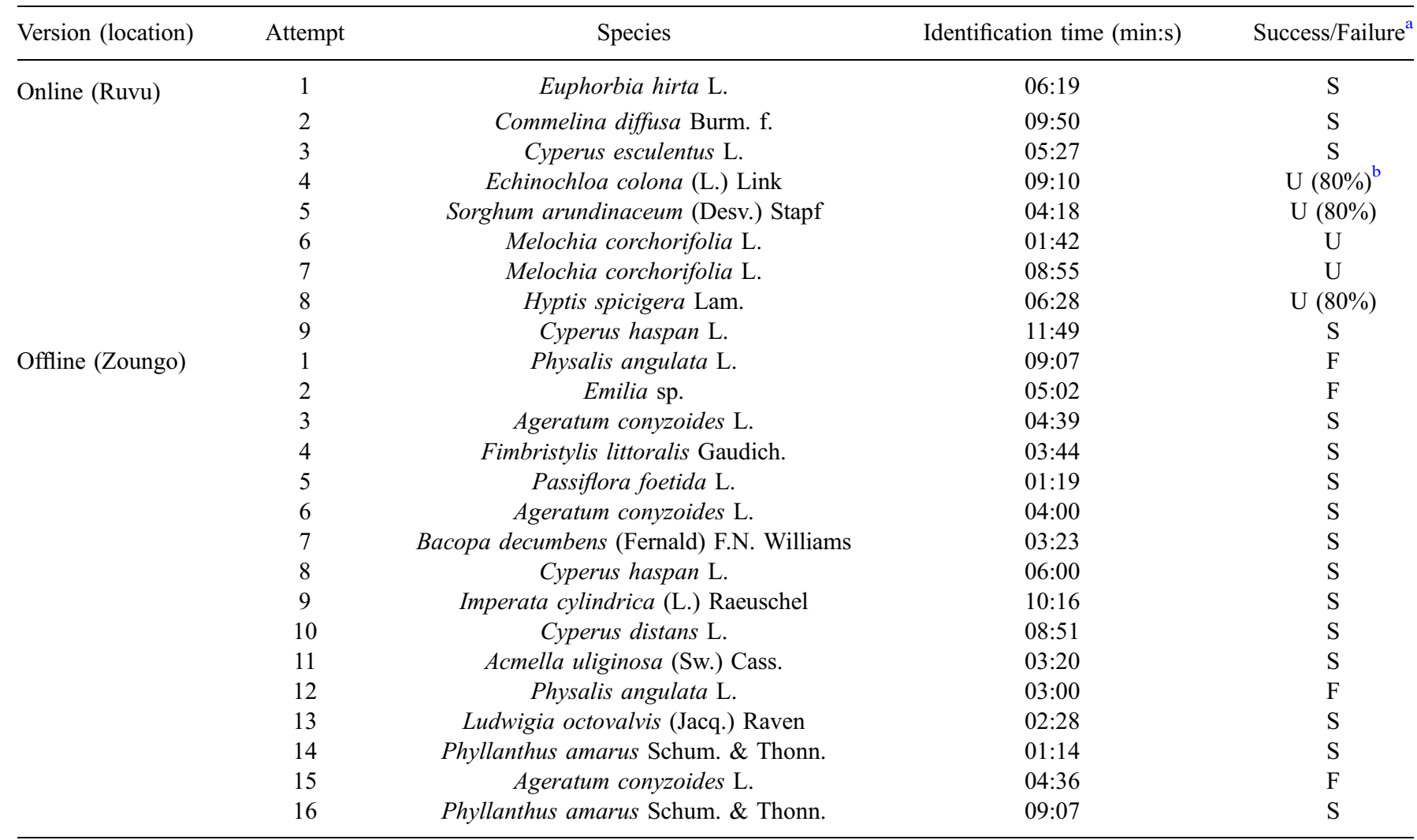

${ }^{\mathrm{a}} \mathrm{S}$ : successful; U: unsuccessful; F: failed.

${ }^{\mathrm{b}}$ The correct species showed $80 \%$ of fit to the selected character.

Portuguese and Swahili should also be considered. The tool could be expanded or improved by integrating image recognition (e.g., Cope et al., 2012; Yanikoglu et al., 2014). A second future consideration would be to couple the identification tool with a weed management tool, such as Weed Manager (Parsons et al., 2009). Part of the team responsible for the development of AFROweeds is currently working on such an electronic decision support tool explicitly focusing on weed management in rice.

\subsection{Discussion on the collaborative platform}

From the online discussion on the usefulness of Weedsbook during the workshop (Fig. 3), it appeared that most participants felt that the online platform Weedsbook, as an African weed science network, will help the advancement of weed science in Africa. This collaborative tool was generally found useful and efficient, as it allows the sharing of information among members and it will help agricultural change agents to update themselves on new developments, to generate new research ideas, and generally to enlarge their professional network thereby creating new opportunities for collaboration. However, language differences may hinder important discussions on the platform. The possibility of adding a translator to the platform, to give at least a rough idea of what is being discussed, was suggested.
Queries were raised on whether the network will be durable and whether it should be opened to agricultural change agents working on crops other than rice, and whether there should be a geographic limitation to Africa. The establishment of a steering committee was proposed to ensure the sustainability of the network. It was also generally accepted that Weedsbook should allow membership from weed scientists and agricultural change agents working on other crops and in other regions if they find it useful. As Weedsbook is an open-access network, it will not exclude anyone with serious intentions who finds the network useful.

There is a great need for better-informed agricultural change agents in SSA, as this is often hampering the provision of useful recommendations to farmers (e.g., Schut et al., 2015a, 2015b). Weedsbook can fulfil this need. Agricultural change agents will find in this platform a receptacle for the wealth of information gathered in the field which would enable them to consider possible solutions that do not emanate only from their local expertise, but also from the scientific community active in the field of weed science. Weedsbook was also believed, by the test users, to have the potential to attract students and young scientists and to motivate them to work on weed problems. To prepare future agricultural change agents to serve farmers with weed problems, students from agricultural colleges and universities form an important additional target group for the tools we have generated. 


\section{Conclusion}

The AFROweeds identification tool and database is a useful instrument for agricultural change agents assisting rice farmers with weed problems in their crop. Where the user is not depending on $3 \mathrm{G}$ network coverage, the identification can be completed in less than seven minutes, with a success rate of at least $75 \%$. Successful and partly successful identifications can then lead the user to factsheets with descriptions of the weed and information on weed ecology, management and local names that facilitate the communication with farmers. For further questions or information as well as for the exchange of experiences and photos, the agricultural change agent can turn to the network Weedsbook. The weed identification tool AFROweeds and the online network Weedsbook are therefore complementary. AFROweeds and Weedsbook were positively assessed by test users and it became clear that their use should not be restricted to agricultural change agents working on rice but also serve those assisting farmers with other crops. Other recommendations were to expand the number of weed species, local names and uses, and to reach out to potential users that are less familiar with English or French as work language.

As ICT products like smartphones, tablets and the internet will become increasingly common, affordable and accessible in sub-Saharan Africa, it is expected that the tool, database and network will gradually and successfully replace the field guides in book form that are currently most often used for weed identification and weed management recommendations. Unlike books, ICT products can be updated regularly. Farmers can benefit from the tool and network through interaction with better-informed and better-equipped agricultural change agents. Improved support to farmer decision-making should lead to better weed management and lower weed-inflicted yield losses, and subsequently contribute to improved food security.

Acknowledgements. All African AFROweeds partners are acknowledged for their contributions to the tool and database, and their participation in workshops and cooperation during the trials. We thank Guy Manners of Green-Ink (UK), for proof-reading and language editing of an earlier version of the manuscript. The tools presented in this paper have benefitted from contributions by G. Kyalo, K. Aloys, N. Ngoc, G. Tzelepogou and K. Iswaria. The EU-ACP Science and Technology Programme is greatfully acknowledged for funding our work under the 'African Weed of Rice (AFROweeds)' project (grant number AFS/2009/219015). This is an output of the CGIAR Research Program GRiSP, the Global Rice Science Partnership.

\section{References}

Akobundu IO, Agyakwa CW. 1987. A handbook of West African weeds. Ibadan, Nigeria: IITA.

Camara M, Kebbeh M, Miezan K. 2008. Intensification of ricegrowing in the lowlands in the district of Sine-Saloum (Senegal). Cah. Agric. 17: 451-455.
Cope JS, Corney D, Clark JY, Remagnino P, Wilkin P. 2012. Plant species identification using digital morphometrics: a review. Exp. Syst. Appl. 39: 7562-7573.

Diagne A, Amovin-Assagba E, Futakuchi K, Wopereis MCS. 2013. Estimation of cultivated area, number of farming households and yield for major rice-growing environments in Africa. In: Wopereis MCS, Johnson DE, Ahmadi N, Tollens E, Jalloh A, eds. Realizing Africa's rice promise. Wallingford, Oxfordshire (United Kingdom): CABI, pp. 35-45.

Grard P, Homsombath K, Kessler P, et al. 2006. Oswald V1. 0: a multimedia identification system for the major weeds of rice paddy fields of Cambodia and Lao PDR. France: CIRAD, Computer Application.

Grard P, Le Bourgeois T, Merlier H. 2010. Adventrop V.1.5. Les adventices d'Afrique soudano-sahélienne. Montpellier (France): CIRAD, Computer Application.

Grard P, Le Bourgeois T, Rodenburg JP, et al. 2012. AFROweeds V.1.0: African weeds of rice. Montpellier (France) \& Cotonou (Benin): CIRAD-AfricaRice, Computer Application.

Ivens GW. 1989. East African weeds and their control. Nairobi: Oxford University Press.

Johnson DE. 1997. Weeds of rice in West Africa. Bouaké: WARDA DFID - CTA.

Le Bourgeois T, Merlier H. 1995. Adventrop : les adventrices d'Afrique soudano-sahélienne. Montpellier (France): CIRAD.

Le Bourgeois T, Carrara A, Dodet M, et al. 2008. Advent-OI : principales adventices des îles du sud-ouest de l'Océan Indien. Montpellier (France): CIRAD, Computer Application.

Nhamo N, Rodenburg J, Zenna N, Makombe G, Luzi-Kihupi A. 2014. Narrowing the rice yield gap in East and Southern Africa: Using and adapting existing technologies. Agric. Syst. 131: 45-55.

Parsons DJ, Benjamin LR, Clarke J, et al. 2009. Weed Manager-A model-based decision support system for weed management in arable crops. Comput. Electron. Agric. 65: 155-167.

Pertot I, Kuflik T, Gordon I, Freeman S, Elad Y. 2012. Identificator: A web-based tool for visual plant disease identification, a proof of concept with a case study on strawberry. Comput. Electron. Agric. 84: $144-154$

Rodenburg J, Johnson DE. 2009. Weed management in rice-based cropping systems in Africa. Adv. Agron. 103: 149-218.

Schut M, Rodenburg J, Klerkx L, Kayeke J, van Ast A, Bastiaans L. 2015a. RAAIS: Rapid Appraisal of Agricultural Innovation Systems (Part II). Integrated analysis of parasitic weed problems in rice in Tanzania. Agric. Syst. 132: 12-24.

Schut M, Rodenburg J, Klerkx L, Hinnou LC, Kayeke J, Bastiaans L. 2015b. Participatory appraisal of institutional and political constraints and opportunities for innovation to address parasitic weeds in rice. Crop Prot. 74: 158-170.

Seck PA, Diagne A, Mohanty S, Wopereis MCS. 2012. Crops that feed the world 7: Rice. Food Secur. 4: 7-24.

Seck PA, Togola A, Toure A, Diagne A. 2013. Propositions for optimizing the performance of rice production in West Africa. Cah. Agric. 22: 361-368.

Yanikoglu B, Aptoula E, Tirkaz C. 2014. Automatic plant identification from photographs. Mach. Vis. Appl. 25: 1369-1383.

Zimdahl RL. 2007. Fundamentals of weed science. London: Academic Press.

Cite this article as: Rodenburg J, Le Bourgeois T, Grard P, Carara A, Irakiza R, Makokha DW, Kabanyoro R, Dzomeku I, Chiconela T, Malombe I, Sarra S, Ekeleme F, Mariko M, Andrianaivo AP, Marnotte P. 2016. Electronic support tools for identification and management of rice weeds in Africa for better-informed agricultural change agents. Cah. Agric. 25: 15006. 